\title{
Mapping the Self in Fleur Adcock's Poetry: From a Postmodernist Sensibility to Postmodern Feminism
}

\author{
Carmen Zamorano \\ Universidad de Lleida
}

One of the main points of controversy between contemporary feminists and postmodernist critics has been Foucault's argument for the "death of the subject." Whereas postmodernism argues against a subject-centred critique, contemporary feminism works in the opposite direction, arguing that women need to discover, and must fight for a sense of identity that, according to Patricia Waugh, will be defined by the individual's "quest for history, agency and self-conscious identity, as aspects of relationships with socially situated others" (31). The contrast between these two opposite positions is at the centre of the controversy between postmodernist and feminist perspectives that has allowed for the definition of a postmodern-feminist framework in which to reach a better insight into the work of some contemporary women poets, whose main concern is the exploration of their own sense of identity. In this paper, I will consider Fleur Adcock's most recent work in this light. I will argue that Adcock seems to have evolved from the expression of postmodernist concerns to a poetry that may be considered within a postmodernist-feminist practice in the British Isles, in which she seems to have found an adequate space for the exploration of her sense of identity, a dominant topic in her poetry.

In his book L'ère du vide, Gilles Lipovetsky defines the postmodern individual as a heteroclite patchwork, a polymorphous combination, true reflection of postmodernism (111). With Lipovetsky's definition in mind, it seems unavoidable to acknowledge Fleur Adcock as a case in point of this postmodern individual. Adcock's life and poetry looks like an amalgamation of opposites. In terms of national feeling, she was born in New Zealand with Anglo-Irish roots, spent most of her childhood in England, but her youth in New Zealand - where she got married - only to go back to settle in England at the age of twenty-nine.

However, this apparently fragmented self does not seem to produce, as observed in her poetry, a sense of sheer inner disruption or insurmountable anxiety. On the contrary, fragmentation creates tension but, at the same time, it seems to have become essential to her. She seems to have internalised the sense of ambiguity and contingency produced by fragmentation, transforming it into the main source of her creative impulse, as can be inferred from her own words:

[Moving back to New Zealand in 1947] I lost my much derided English accent and, after a time, some of my sense of cultural displacement. I learned to live with an almost permanent sense of free floating, unfocused nostalgia, and with the combination of crushed humility and confident arrogance that comes from not quite belonging. It is not a bad thing to be an outsider, if one wants to see places and events clearly enough to write about them. At any rate, an outsider seemed to be what, after so much practice at it, I had become. (Gregson 84) 
This theme of cultural displacement and her experience of rootlessness are central to Adcock's early poems and, as Ian Gregson points out, "the physical displacements she has experienced can be seen as analogues for other, more complex psychological displacements which raise questions about identity" (84). Although this sense of cultural displacement starts to see the light in High Tide in the Garden (1971), her first collection published in England, it only comes to full growth in the two collections that followed.

The Scenic Route (1974) seems to mark the beginning of Adcock's evolution from an exploration of her own psyche through nostalgic memories of her childhood, dominant in her early works, to a more dialogic construction of subjectivity, in which her sense of self is defined in her poems through a growing concern with socio-historical and political issues. This evolution seems to reflect a shift from the post-Movement's principle of "truth to experience" (Stannard 18)-leading to an English type of "confessional poetry"- to the poetry engagé that dominated the late 1960s and 1970s. However, throughout the collection there is also a clear attempt to reach a balance between apparently contrary positions, that is, between confessional and committed poetry, between the private-generally regarded to belong to women's sphere-and the public_-men's area.

The second poem in this collection, "Please Identify Yourself," seems the best evidence of the change perceived in Adcock's poetry to define her much fragmented identity-apparently placed somewhere between Ireland, Great Britain and New Zealand. Whereas her earlier poems are primarily concerned with the search of self through the exploration of her inner landscapes and engaging in merely an inner dialogue, The Scenic Route introduces the element of the public voice and the sense that the self can only exist in and be defined by space and time, what Bakhtin defines as a chronotope. Adcock's incapacity to identify the specific components of this chronotope results in an incapacity to identify her own identity and, consequently, in an urgent ambiguity and ontological indeterminacy, characteristic of the postmodern individual and which is perfectly expressed in the opening line of this poem: "British, more or less; Anglican, of a kind."

This sense of ambiguity pervades the rest of the stanza in the form of understatement, a much English feature, paradoxically used by someone with splitting doubts about her own Englishness. The common and apparently harmless question-pronounced in the poem by the bus driver that is taking her to her ancestors' home town-about someone's place of origin turns into a despairingly "[u]nanswered" (and so far unanswerable) question, as implied by the comparison in "the less urgent question" (2), whose second term of comparison is tellingly omitted. When forced to give a simple reply to what is innerly-felt as a complex question, Adcock takes the safest route, namely, to mention the place where she was born, even though, as suggested by some of her previous poems and by her describing this option as "a cowardly retrogression" (5) the reader is left to infer how misleading such an answer is.

This liminal sense about her own national identity and the dishonesty implied in adscribing to a single nationality seems to mirror the situation in Ulster, "where sides have to be taken" (12), even though affirming to be Catholic, Protestan or Presbyterian seems to be a blatant oversimplification of one's subjectivity. The question of identity cannot be re- 
duced to a simple labelling. Consequently, when forced to take one side or the other, Adcock's compromise is precisely to "stop compromising" (13) and, learning from the bones of her own ancestors that were not labelled in their graves as Catholics or Protestants, she seems by the end of the poem readier than at the beginning to "embrace" (40) all differences under the umbrella term of identity.

However positive this pluralism might seem in this case, contemporary critics of postmodernism-many of them from feminist quarters-have pointed out the danger of this so postmodernist all-inclusive pluralism. The defence of such position partly stems from the postmodernist critique of the modernist concept of a unified self. The postmodernist rejection of the subject-centered inquiry and theory has been seen with suspicion and hostility by many feminist critics, since as Jane Flax (1987) argues, "the postmodernist suspicion of the subject effectively prohibits the exploration of (a repressed) subjectivity by and on behalf of women" (Di Stefano 75). It is precisely under these postmodernist "pressures" that Adcock wrote Below Loughrigg (1979) and The Incident Book (1986).

As Adcock herself states, during her stay in the Lake District, on her first literary fellowship, she tried to overcome a minor literary crisis. The result of such an attempt was Below Loughrigg, where some of her poems revealed what was at the centre of her literary worries at the time:

[in some of the poems] I found myself increasingly inhibited by a severe distaste for the first person: I simply couldn't bring myself to write "I" yet again. As a result there are several poems from that period where the syntax is unusually contorted, in order to exclude pronouns as far as possible and to accommodate what was actually a first-person view-point without the use of "I." (McCully 155)

The origin of this crisis might be found in the postmodernist critique of the subjectcentred inquiry or what Foucault proclaimed in his essay "What is an Author?" (1977) as the "death of the subject." Given the growing recognition of Foucault's statement among postmodernist theorists and in literary practice, it is not strange that Adcock might have felt a certain unease at the use of the strongly personal voice that had characterised her poetry until then.

The end to this crisis only came with "Personal Poem," significantly included at the centre of The Incident Book. In this poem, which Adcock herself calls "a calculatedly impersonal piece of writing," (McCully 155) she parodies her concern with using an obviously "lyrical I" and ends up dismissing such a concern as merely belonging to "abstract theory" (McCully 156), suggesting that such abstractions have nothing to do with her understanding of poetry. It is in this sense that The Incident Book may be said to mark a clear shift of sensibility in Fleur Adcock's poetry: firstly, she has moved from an essentially personal tone in her early poems to a wider range of concerns, thus becoming more involved with her own times. Secondly, she has definitely abandoned her driftings towards the postmodernist "death of the subject" and has veered towards a decisive recognition of her perspectivalist position, which Anne Yeatman (19-20) has identified as one of the main features of postmodern feminism. As Yeatman argues: "All knowledge is situated knowledge, and is governed by the perspective of those who are the knowers. . . Since the sub- 
jectivity/positioning of the knowers is historically variable and specific, the perspectivalist base of knowledge renders all knowledges historically specific" (19). This perspectivalist position is first assumed in The Incident Book, but will only come to be fully developed in her following books, Time-Zones (1991) and Looking Back (1997).

In Time-Zones, Adcock seems to have become more assured of her perspectivalist stance, of the rightful use of a highly personal and subjective point of view-thus denying the postmodernist argument for the death of the subject-as well as of the fruitful interference of the private into the public so as to denounce many of the dangers of our postindustrial and postmodern world. The combination of the public and the private in Adcock's poetry does not lead to the disappearance of both spaces in an anxious homogeneization, of the kind suggested by what Baudrillard called "hyperreality" or "the ecstasy of communication" (130). Rather, it is aligned to the type of postmodernism of resistance that can be observed in Edward Said's defence of a committed literature:

Instead of noninterference [in public issues] and specialization, there must be interference, crossing of borders and obstacles. ... One of the first interferences to be ventured, then, is a crossing from literature, which is supposed to be subjective and powerless, into those exactly parallel realms, now covered by journalism and the production of information, that employ representation but are supposed to be objective and powerful. (157)

The attempt to reach a balance between the private and the public spaces seems to be suggested by the very structure of the collection. The topic of death and related themes - aging, illnesses and their possible causes-seems to be the common thread uniting the poems in this collection. Whereas the private voice and inward look of the poet prevails in the first half of the book, in the second half of Time-Zones, Adcock assumes the role of the poet as a social commentator raising her voice about environmental issues-the damage of the environment in "The Greenhouse Effect" or the hunting of species in danger of extinction in "The Last Moa"- politics - the situation in Romania, dealt with in "On the Way to the Castle" and "Romania"-and gender-like in "The Batterer." The role of political commitment that has been forced upon poetry since the late 1960s becomes the topic in "From the Demolition Zone," in which literature is invoked as the new saviour against the ills of our foul contemporary world: "Come, literature, and salve our wounds" (1). Literature is elicited to take over science and rational thinking to fight for and protect society against any harm:

Clear-eyed literature, diagnostician, be our nurse and our paramedic.

Hold your stethoscope to our hearts and tell us what you hear us murmuring.

.....................

You know what we're afraid of saying in case they hear us. Say it for us. (7-10; 17-18)

However, the sacred tone of the poem and its grandiose style, together with the widely social reference of the pronoun "we" establish such a contrast with the intimate tone and private voice of the first poems in this collection that the reader cannot but, at least, be wary of how Adcock is going to negotiate this "interference" of her poetry in public issues. 
In his review of Time-Zones, Alan Jenkins expressed his most intense disappointment at what he considered to be the presence of "under-achievement and irresolution about Fleur Adcock's new book." Jenkins identified the presence of both the private and the public voice in her poems. However, while praising the "undisputed glories" of the poems emerging from Adcock's private sphere-those included in the first half of the collectionhe regretted the apparent lack of quality of the poems produced from the perspective of "the other voice," and Adcock's yielding to the commercial views that seems to have penetrated into the literary sphere in postmodern culture:

This voice is required to make heartfelt, emphatic statements tailored to the demands of the international poetry event and flattering the audience's eagerness to "respond" while being entertained, and it loses in its evolution towards clarity, simplicity and so on, most of what makes Adcock's work in her "natural" voice so subtle and memorable.

However, I would like to argue that what Jenkins perceives as the private being superseded by the public in Adcock's poetry-with all the negative consequences derived from it-is actually an incorporation of a new facet into her poetry, in accordance with the literary and socio-political context in which this is produced. Thus, the public and the private are not seen as mutually exclusive. Much on the contrary, both spheres seem to engage in a dialogic relationship with positive effects on both sides. Romantic idealism and essentially subjective writing of the past are effectively adapted to the socio-political requirements of postmodern culture.

Between the intensely subjective poems of the first part of Time-Zones and the passionately revolutionary tone of the poems of the second part, Adcock offers a view of what she understands as politically committed poetry, namely, one lying between these two extreme positions, in which the private experience of the dangers of our current world serves, in turn, to denounce them. The remaining sections in the collection seem to function as a practical example of Adcock's poetry engagé. Thus, "The Farm" and "Aluminium," included in "Causes," the second section in this collection, denounce environmental damages as the cause of cancer and Alzheimer, respectively. What makes these poems most effective is the substitution of the plural subject- "we" used in "From the Demolition Zone"-by the singular form, which makes it easier for the reader to feel identified with the character in these poems, and, thereby, to receive the political message at a more personal level.

This balance between the private and the public voices in Adcock's poetry is also observed in her latest collection, Looking Back (1997) with regard to gender issues, which have slowly become increasingly present in her poetry. Adcock's acknowledgement of her concern with women's issues in poetry is marked by her introduction to the anthology she edited for Faber, The Faber Book of Twentieth Century Women Poets (1987). In this introduction, Adcock criticises the ghettoising effect that radical feminism-as it had been practised since the late 1960s - had had for women writers, who, in their attempt to make their voices heard, had discriminated against male writers and readers, thus making the same mistake as the patriarchal tradition they attacked:

The danger is that women's poetry will be shunted into a ghetto. ... Part of this could be blamed on women themselves, or on certain women writers, who take a radically separatist 
attitude, rejecting "patriarchal standards" and "the language of the oppressors," claiming that men do not understand the tones of voice in which women express themselves, and addressing their work exclusively to other women. (2)

For this reason, Adcock expresses her dislike of the category of "women poets" and the existence of a specifically women's poetic tradition, because, as she sees it, "women have been involved in the currents and movements as little or as much as men, and have been as various" (1). What Adcock and many other women writers seem to reject is not their femaleness or their being "women poets," but the fact of being considered above all-if not exclussively - "women poets." As argued by many contemporary feminist critics, a woman's self-identity is not to be defined by single categories, since it is a compound of many other factors, like race, class, religion, nationality, to name but a few. It is only through a dialogic relationship between all these identities and of the individual with other male or female subjects, through a reconciliation of all these differences that a woman can achieve a sense of self-identity. As Allison Weir argues,

Ideally, these reconciliations are achieved not through the imposition of an identity which excludes or represses difference and non-identity (the concern of post-modernists), but through a capacity to reflexively and practically accept, live with, and make sense of differences and complexity. This capacity is based not on a denial of connections with others (the concern of relational theorists), but on a cognitive and affective acceptance of intersubjectivity and autonomy and of the dependence on and independence from others. ... (265)

As Adcock suggests in her latest collection, these repressed differences are to be found in the (hi)stories that have been submerged by a monological tradition and view of history (Lyotard's grand récits). Some of these (hi)stories have gender and feminist issues at their centre, with female protagonists raising their voices to directly or indirectly proclaim their stories of discrimination and oppression by the socio-historical order at their time. However, the submerged stories of male ancestors are also shown to be relevant for Adcock's construction of her own sense of self-identity.

As Gillian Allnutt pointed out in her review of Adcock's latest collection for Poetry Review, "There's a nice symmetry to Looking Back. In the first part we meet Adcock's ancestors-backwards, as one traces one's ancestors. ... In the second part, where all the poems are personal and many autobiographical, we move among the living generations of the family. .." (95). However, the relation between both parts seems to stretch deeper than a balance between past and present, ancestors and devotee(s)-to borrow Adcock's words in her poem "Ancestor to Devotee." The second part seems to be the logical consequence of Adcock's understanding of history, which she acquires in the process of constituting her self-identity through a dialogue with the "other"- - her ancestors.

The dialogic relationship between past and present and between the private and the public is emphasised by the shift of narrative voice, when the voices of Adcock's ancestors come into the poems to reveal their own private story. By introducing these private stories into the literary discourse, they acquire a broader significance and become an indirect criticism to a specific socio-political situation with application to Adcock's specific time and place, that is, to her specific chronotope. Thus, "Mary Derry" describes the story of Ad- 
cock's female ancestor ${ }^{1}$ - told in first person singular-who felt forced to marry after becoming pregnant, a sin —or so she thought it was-and a sense of guilt that seemed to haunt her to the grave. This moral pressure is apparently inflicted upon her by the strict mores of England of the turn of the nineteenth century. However, the causes of this private anguish are not explicitly stated in the poem, but left to be inferred by the readers of the late 1990s, who, thirty years after the upsurge of feminism, are already prepared to identify the attack against such strict morality, and even to identify it with a similar type of discrimination in their own time, that is, discrimination against single motherhood. In this way, the reader of this story becomes the "other" and "interlocutor" in the creative process. As Bakhtin pointed out, this is an active other who is asked to interpret the message that $\mathrm{s} / \mathrm{he}$ is handed in through the poem: "And what I have to ask is: / was it [consumption inherited from her by her male forebears] the city's fault, or mine? / You can't answer me” (41-43). Through this dialogic relation, both the self of the past and the present reader are joined together in a subversive act against monological power structures, namely, social and sexual mores of their respective context.

The contrast between history and (hi)story is most evident in "At Baddlesley Clinton." In this poem, like in "Frances," though with a male ancestor at the centre, two texts are interwoven, namely, the official text on the memorial-clearly distinguished in the poem by the use of capital letters and its being "framed" by inverted commas-and the unofficial and non-linguistic text of the indelible blood printed on the oak floor of Nicholas Brome's "upstairs parlour, near the hearth" (2). This "splodge of blood" (1) is testimony to the story of a crime of passion, in which Adcock's ancestor murders his wife's lover. The fact that the lover was a priest brings the political and religious implications into the case, linked with the way in which "the villain" (4) in Adcock's family seemed to buy his pardon: "But he got the King's and the Pope's pardons, / and built the church a new west tower" (17-18). The interrelation between the private and the public stories in the poem serves to suggest another story, this time being one of corruption within political institutions-monarchy and the Church-that discredits them and deprives their discourse of authority. This undervaluing of official history is opposed to the validation of this story of passion that had been submerged by institutional powers, but which seems to come to public attention five centuries after its occurrence:

His other memorial was more furtive;

it trickled down under the rushes

and stayed there. Easy to cover it up,

but more fun now for the tourists

to see it crying out his crime.

It is blood: they've analysed it.

On some surfaces, in some textures,

blood's indelible, they say. (23-28)

\footnotetext{
${ }^{1}$ As pointed out in the endnotes added by Adcock to Looking Back, "Mary Derry married William Eggington in 1800 and was the great-great-grandmother of Samuel Adcock's wife Eva Eggington [Adcock's paternal grandparents]" (67).
} 
Despite the attempt of institutional powers to offer their view of the world as the only Truth, the "other" (hi)stories are always present under the surface and, being indelible, will eventually and inevitably come up to the surface.

To conclude, I would like to recover two significant lines from one of Adcock's poems included in Below Loughrigg: "I am the dotted lines on the map: / footpaths exist only when they are walked on" ("Paths," 1-2). Adcock's poems are a continuous attempt to map her own self by negotiating differences. Her "condition of being," to use Yeatman's words, "is the discursive space of 'in-between' or of 'hybridized' identities" (19). The exploration of the land of her ancestors and of the land where she was born had served Adcock in her previous collections as an attempt to map her own self through the mapping of those elements of the past that seemed to be at the centre of her sense of rootlessness and cultural displacement. In Time-Zones, there was an attempt to study the interrelationship, not only of different places, but of places and times in the formation of one's subjectivity; and, in Looking Back, Adcock tries to map her own self through the mapping of her own genealogy. What makes Adcock's genealogy most outstanding is her emphasis in incorporating historical facts, legends and the workings of her own imagination to define her own family history and, thereby, shape her own sense of self-identity. Thus, it can be observed how Fleur Adcock's own (hi)story is one of in-betweenness, of not belonging completely to a specific place, but finding the definition of her own self in the "dotted lines" that mark the joint, or what Annamarie Jagose's terms as "suture" (Yeatman, 19), between different places, different times, and also between different genders.

\section{WORKS CITED}

Adcock, Fleur, ed. The Faber Book of Twentieth-Century Women Poets. London: Faber, 1987.

Looking Back. Oxford: OUP, 1997.

Selected Poems. Oxford: OUP, 1983. This includes a selection of work from several collections: The Eye of the Hurricane (1964); Tigers (1967); High Tide in the Garden (1971); The Scenic Route (1974); and The Inner Harbour (1979).

—. Time-Zones. Oxford: OUP, 1991.

Allnutt, Gillian. “Genealogies.” Poetry Review 88.1 (1998): 95.

Baudrillard, Jean. "The Ecstasy of Communication." The Anti-Aesthetic: Essays on Postmodern Culture. Ed. Hal Foster. Seattle, Washington: Bay Press, 1983. 126-34.

Di Stefano, Christine. "Dilemmas of Difference: Feminism, Modernity, and Postmodernism." Feminism/Postmodernity. Ed. Linda J. Nicholson. London: Routledge, 1990. 6383.

Gregson, Ian. Contemporary Poetry and Postmodernism: Dialogue and Estrangement. Basingstoke: Macmillan, 1996. 
Jenkins, Alan. "Global Warning on the Conference Circuit." Independent on Sunday 26 May 1991.

Lipovetsky, Gilles. L'ère du vide: Essais sur l'individualisme contemporain. Paris: Gallimard, 1983.

McCully, C. B., ed. The Poet's Voice and Craft. Manchester: Carcanet, 1994.

Said, Edward W. "Opponents, Audiences, Constituencies." The Anti-Aesthetic: Essays on Postmodern Culture. Ed. Hal Foster. Seattle, Washington: Bay Press, 1983. 135-59.

Stannard, Julian. Fleur Adcock in Context: From Movement to Martians. Lewiston: The Edwin Mellen Press, 1997.

Waugh, Patricia. "Postmodernism and Feminism: Where Have All the Women Gone?" Feminine Fictions: Revisiting the Postmodern. London: Routledge, 1989. 1-33.

Weir, Allison. "Toward a Model of Self-Identity: Habermas and Kristeva." Feminists Read Habermas: Gendering the Subject of Discourse. Ed. Johanna Meehan. London: Routledge, 1995. 263-82.

Wilmer, Clive. Poets Talking: The 'Poet of the Month' Interviews from BBC Radio 3. Manchester: Carcanet, 1994.

Yeatman, Anne. "The Epistemological Politics of Postmodern Feminist Theorizing." Postmodern Revisionings of the Political. New York: Routledge, 1994. 13-26. 